\title{
Research on the Concept and Measurement Dimension of the Service Environment based on the Perspective of Ecological Psychology
}

\author{
Lai Wei \\ School of Management \\ Wuhan University of Technology \\ Wuhan China \\ e-mail: 1vv030609@126.com
}

\author{
Cheng Yanxia \\ School of Management \\ Wuhan University of Technology \\ Wuhan China \\ e-mail: chengyanxia221@126.com
}

\begin{abstract}
The ecological psychology holds that the human behavior is the result of the interaction between human and environment. And in a certain service context, the customer behavior is not only affected by the physical environment, but also by human which is an important factor. Based on the theory of ecological psychology and service environment, the paper redefines the concept of service environment and analyzes its connotation. On this basis, the paper also discusses the measurement dimensions of service environment from two aspects of physical environment and social environment.
\end{abstract}

Keywords- ecological psychology; service environment; concept; connotation; measurement dimensions

\section{INTRODUCTION}

With the increasingly serious service products homogenization phenomenon, the service environment is constantly becoming important and plays a more and more obvious role in the reality. In order to build a better service environment to meet enterprises' need, it's necessary to discuss deeply its concept and measurement dimensions. In the present study, scholars trend to define the service environment as a place where customers accept some services, including the invisible and visible environment. While among them, the invisible environment refers to the atmosphere, music and other factors, and the visible environment refers to the specific physical facilities. All studies are not involved in the "human". Similarly, most of the dimension studies of service environment are focused on the physical environment while lack of the social factors. The ecological psychology shows that the human behavior is the result of the interaction between human and environment. In some service situations, the customer behavior is not only affected by the surrounding physical environment, but also affected by the surrounding human, such as the service employees, other persons and surrounding persons, and so on. Especially the impact of service employees, it would directly determine customers' service experience, and then affect the evaluation of customers to service environments. Therefore, the service environment can't be simply divided into the "visible" and "invisible" dimensions, but also should include the "human" dimension. Based on this analysis, the paper would integrate the social dimension "human" into the service environment and then redefine its concept, connotation and measurement dimensions according to the idea of ecological psychology theory.

\section{DEFINITION AND CONNOTATION OF SERVICE ENVIRONMENT}

\section{A. Literature review}

In 1973, Philip Kotler published an article entitled "Atmospherics as A Marketing Tool" in the "Retailing Journal", which opened the research history of service environment. It is considered that the service environment covers the environmental factors which can be perceived by the senses of seeing, hearing, smelling and touching. Since then, scholars have studied the concept of service environment in different degrees. Through having studied the bank service environment, Lovelock(1989) ${ }^{[1]}$ thought for customers, the bank service environment refers to those visible and invisible displays in the service fields which could weaken the impact of customer awareness to service intangibility and could be felt from the sense of seeing, hearing, smelling, and so on. Bitner (1990) ${ }^{[1]}$ defined the service environment as all entities that may be exposed to customers and the "soft environment", such as the staff dress, in a service encounter. Chen Jue $(2005)^{[2]}$ defined the service environment as a physical environment where servants could provide services and customers could experience services. It's a service product yieldly, a consumption place and a material carrier of service, which include all kinds of hardware facilities, equipment and material space. Zhang Zhengang \& Xiao Tianye ${ }^{[3]}$ (2006) extended the service environment concept to the visible display and considered the service environment not only shows service itself by the service situation or the product appearance related to service, but also regards overcoming the service intangibility as a ultimate goal. It provides tangible or easily perceived clues for intangible services. Shi Jianzhang $(2013)^{[4]}$ defined the service environment as the tangible hard environment such as some related service facilities, spatial arrangements and so on, and some soft environment affecting customer perception such as staff dress, background music and so on.

In summary, there are some limitations in the definition of service environment in current, that is, scholars tend to define the service environment as a kind of physical environment and ignore the "human" factor. In fact, the service environment that customers facing not only includes the physical environment, but also should include 
the social environment, which means that in service encounters, customers would not only affected by hard facilities, equipment and material space, but also by "human". And it' $s$ the same with the main idea of ecological psychology theory: "The human behavior is the result of the interaction between human and environment". Therefore, this paper redefines the concept of service environment making use of the basic idea of ecological psychology theory.

\section{B. Concept and connotation}

The ecological psychology theory advocates that the human behavior is the result of the interaction between human and environment. In a certain service situation, customer behavior is not simply the result of the environment, but the interaction between human and environment, that is, the service environment customers facing not refers to a simple tangible and intangible environment, but also contains "human" factors. Based on this analysis and referring to the domestic and foreign studies on service environment concept definition, the paper defines the service environment as the physical and social environment which could be perceived by customers when experiencing some service. And the physical environment refers to those tangible and intangible factors in service, such as hardware facilities, material space, music, design, and so on, while the social environment refers to those factors like service employee and other persons who would be exposed to the service encounter.

1) The service environment is reflected by the customer perception.

The purpose of enterprises creating a good service environment is to improve customer perceived value. Therefore, as a person who directly experience the service environment, customers have a decisive evaluation of the merits of enterprise service environment. The advantages and disadvantages of enterprise service environment are completely reflected or judged by customer perception.

2) The service environment is an organic combination of the physical and social environment.

All enterprises must rely on some certain physical environment construction when providing services and would involve many people including customers, employees and others at the same time. As a result, every service environment provided by enterprises can not only include the physical or social environment, but must be an organic combination of the physical and social environment. Only in this way, the enterprise could provide the best service for customers.

3) The physical environment is the foundation of building a service environment, while the social environment is the guarantee of providing a high-quality environment.

For a service enterprise, it must first build the most basic service facilities, that is, build physical environment foundation, in order to build a good service environment. Otherwise, the service provided by enterprises would lose its carrier. While, if an enterprise wants to provide a highquality service environment, it's necessary to train excellent service employees and maintain a favorable service order which means maintaining the interaction among customers, service employees and others; that is, to provide social environment guarantee. Otherwise, the customer perceived service value would be reduced.

\section{MEASUREMENT DIMENSIONS OF SERVICE ENVIRONMENT}

\section{A. Design idea}

Currently, the main domestic and foreign scholars' researches on the measurement dimensions of service environment are: $\operatorname{Baker}(1987)^{[5]}$ divided the retail environment into the surrounding conditions, design and social factors; Belk et al.(1988) ${ }^{[6]}$ divided the service environment into the surrounding conditions, space arrangements, marks and artificial products; Baker et al.(1988) ${ }^{[5]}$ distinguished the division criterion of service environment dimensions in the minds of customers and employees, and put forward the five dimensions of service environment including the surrounding conditions, aesthetics, privacy, efficiency and social conditions; Ornstein $(1990)^{[7]}$ put forward three dimensions including the surrounding conditions, psychological geography and architectural features; Greenland et al. $(2005)^{[7]}$ gave seven dimensions: physical elements, physical conditions, unique, modern, personal conditions, design and open; He yun \& Wang Xiaochun $(2006)^{[8]}$ divided it into two dimensions of physical environment and social environment. From all these divisions, it would be known that currently the service environment tends to be divided into two dimensions: the hard environment and the soft environment. The hard environment refers to all physical objects such as the decorations, space arrangements, equipment, and so on. The soft environment includes all surrounding factors like temperature, humidity, luminosity and sound in a certain service situation. In addition, the soft environment also includes the staff dress and customer group state which refers to the characteristics of customer groups, such as gender, social level, etc. Similarly, it would be easily known that scholars ignored the "human" factor when dividing the measurement dimensions of service environment. This makes enterprises only paying attention to physical environment and completely ignoring social environment when they evaluate or build their service environment according to these measurement dimensions. Therefore, based on the ecological psychology theory and the redefinition of service environment concept, the paper would re-divide the measurement dimensions of service environment.

\section{B. Re-division}

According to the redefinition of service environment concept, the service environment includes two dimensions of physical environment and social environment. There are more abundant about the research results of physical environment factors. At present, the conclusion proposed by Bitner is more adopted which the physical environment includes fours aspects of space, mark, equipment and surrounding condition. The mark refers to some signs in the service environment like posters, indicator, etc. While the space refers to the space arrangements of a certain service environment. The text argues that the mark is an important factor for the effect of space arrangement, so these two factors could be combined. As a result, in this paper, it is considered that the physical environment includes three factors: space, equipment and surrounding 
condition. While the so-called social environment refers to the customer's social environment in a certain service environment, that is, all other groups may be exposed to the customer at that moment, including service employees and other persons (Table I ).

TABLE I . The MEASUREMENT Dimensions of SERVICE ENVIRONMENT

\begin{tabular}{|c|c|c|}
\hline \multirow{2}{*}{ Service } & $\begin{array}{c}\text { Physical } \\
\text { environment } \\
\text { dimension }\end{array}$ & $\begin{array}{c}\text { Surrounding } \\
\text { condition }\end{array}$ \\
\cline { 2 - 3 } environment & $\begin{array}{c}\text { Social } \\
\text { environment } \\
\text { dimension }\end{array}$ & Squipment \\
\cline { 2 - 3 } & Service employee \\
\cline { 2 - 3 } & & Other persons \\
\hline
\end{tabular}

1) Surrounding condition

This mainly refers to the characteristics of environmental surrounding condition, including a series of potential and intangible elements, such as temperature, light, music, taste, smell, color, etc. Although these elements are inconspicuous, it would still make a great effect on customer emotion through human senses and then affect the customer's behavior intention. At the same time, a series of factors in the surrounding condition dimension are the initial contact of customers to service enterprises, and also the judgement basic of first impression of customers to its service environment. When the surrounding condition dimension is contrary to the customer's expectation, it will produce an extremely strong effect on customer perception and customer emotion, which would directly determines the customer resistance behavior. For example, when facing a messy and hot restaurant, customers are most likely to leave.

\section{2) Space}

This mainly refers to the space arrangements of service environment, including reasonable facilities display, effective identification indicators, etc. When customers enjoy the service, it will directly affect customers' judgements to its service environment that whether the space is enough or not, whether the facilities display is reasonable or not and whether the service indicators are in place or not, which is also a premise to guarantee a smooth service process.

\section{3) Equipment}

This mainly refers that whether the service equipment provided by service enterprises is operated easily or not, matches the service or not, and meets the customers' functional requirements or not. Enterprises providing a good service environment is to achieve some service purposes and meet customers' needs at utmost, which must rely on a certain series of equipment to complete. Therefore, it's extremely important to maintain an excellent equipment in a service environment. Especially in some self-service environment, if the service equipment fail to meet customers' demand, it will directly influence customer emotion, so as to determine customer behavior. Even in a few inter-service environment such as hotels, it will also directly influence customer emotion that whether the elevators, rooms and restrooms are good or not.

\section{4) Service employee}

This mainly includes the professional degree, appearance cleanliness and service attitude. In addition to some self-service environment, most of other service are directed by service employees. So it could be said that the service employee is most close to customers and a major factor that determines customer emotion and behavior. A service employee with high profession, clean appearance and good attitude could provide customers with highquality service. While such a service could offset the customer negative emotion caused by other adverse factors in a certain degree, so as to guide customer positive behavior intention.

\section{5) Other persons}

This mainly refers to the quantity, behavior and evaluation of other persons in the service environment. In any service environment, customers would encounter many other persons except for service employees, including other customers, maintainers, cleaning staff and even other non-related person, etc. And the impact of these persons on customers could not be ignored, especially the impact of other customers. When in a certain service environment, customers will be consciously to obtain many information from surrounding other customers whether they are before consumption, in consumption or after consumption. If facing a number of other customers, customers will give up consuming because of the cost of time; if other customers have some adverse behaviors, it will negatively influence customer emotion; if there're many negative evaluations of service from a lot of other customers, it will directly determine that customers would avoid consumer behavior.

\section{CONCLUSION}

Service environment directly affects customer emotion and then determines the customer behavior intention, so enterprises must pay high attention to the design of service environment. Based on the main idea of ecological psychology theory, this paper put forward the new concept and connotation of service environment combining human with environment tightly and proposes that service environment is an organic combination of the physical and social environment. It still deeply analyzes the connotation of service environment and raises its specific measurement factors from two aspects of physical and social environment, including surrounding, space, equipment, service employee and other persons.

\section{REFERENCES}

[1] BITNER, M. J.. Services capes: the impact of physical surroundings on customers and employees[J]. Journal of Marketing, 1992, 56(2):57-71.

[2] CHEN Jue. DFMC review and research direction based on service industry [J]. Science and Technology Progress, 2005, 19(9), 198200.

[3] ZHANG Zhen-gang, XIAO Tian-ye. The tangibilities of intangible service [J]. Commercial Research, 2006, 63(09):208-212.

[4] SHI Jian-zhang. Service quality dimensions measurement and factor analysis in banking sector [J]. Economic Survey, 2013, 18(4): 94-98.

[5] BAKER, JULIE. The role of the environment in marketing services: the consumer perspective in the Service Challenge $[\mathrm{J}]$. Integrating for Competitive Advantage, 1987,7(6):79-84

[6] BELK. The sacred and the profane in consumer behavior: theodicy on the odyssey [J]. Journal of Consumer Research, 1988,16(6):1-38 
[7] GREENLAND STEVE. Evaluating the design of retail financial service environments [J]. International Journal of Bank Marketing, 2004, 23(2/3):132-152

[8] HE Yun, WANG Chun-xiao. A research review of customer emotion [J]. Academic Research, 2006(7):57-61.
[9] ENGEL J. F., BLACKWEL R.D., MINIARD P. W. Consumer Behavior [M]. New Yokr: Dyrden, 1995.

[10] JAMES A. FITZSIMMONS, MONA J. FITZSIMMONS. Service Management: Operations, strategy and information technology [M]. New York: McGraw-Hill, Inc., 1998 